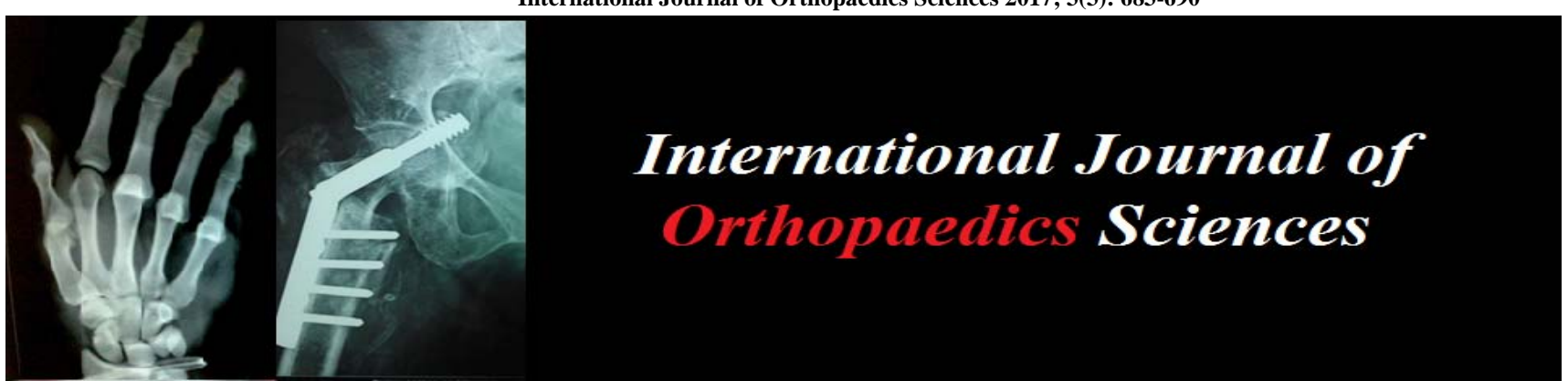

ISSN: $2395-1958$

IJOS 2017; 3(3): 683-690

(C) 2017 IJOS

www.orthopaper.com

Received: 12-05-2017

Accepted: 14-06-2017

Dr. Sagar Balasaheb Kadam DNB Ortho. Senior Resident. Government Multispeciality Hospital, Chandigarh

Dr. Umesh Nagrale DNB Ortho. Senior Resident, Government Medical College, Chandrapur, Maharashtra, India

Dr. Irfan Sheikh

DNB Ortho. Senior Resident, Hinduja Hospital, Mumbai,

Maharashtra, India

Dr. Tirth Vyas

DNB Ortho. Resident, Port

Trust Hospital, Wadala,

Mumbai, Maharashtra, India

Correspondence

Dr. Umesh Nagrale

DNB Ortho. Senior Resident,

Government Medical College,

Chandrapur, Maharashtra, India

\section{A prospective study of outcomes of intramedullary nailing of proximal third shaft tibia fractures}

\author{
Dr. Sagar Balasaheb Kadam, Dr. Umesh Nagrale, Dr. Irfan Sheikh and \\ Dr. Tirth Vyas
}

DOI: http://dx.doi.org/10.22271/ortho.2017.v3.i3j.105

\section{Abstract}

Introduction: Tibia is the most commonly fractured long bone in the body. Among the total tibial fractures, about $5-11 \%$ of fractures occur in the proximal one third of the tibia. Fractures of the proximal third of the tibial shaft, by virtue of being high-energy injuries, are less amenable to plating primarily because of soft-tissue problems, and plates delay weight bearing. External fixators can lead to pin-track infections and there are technical difficulties in preserving knee motion in these juxta-articular fractures. Hence, Interlocking nail remains as an option with benefits of load sharing, sparing the extraosseous blood supply, lesser chances of infections and avoidance of additional soft-tissue dissection, thereby minimizing the risk of postoperative complications. Also allows early joint mobilization and weight bearing with short hospital stay.

Aim: To study the clinico-radiological and functional outcome of the patients with proximal one third tibial shaft fractures managed with interlocking nail.

Materials and Methods: This Prospective Study consisted of 20 adult patients of either sex with proximal one third tibial shaft fracture managed by Interlocking Nail. Functional outcome was measured by the Johner and Wruh's Criteria. Twenty patients were followed for minimum 6 month with fracture healing time was $12-18$ weeks.

Results: After the end of 6 months follow up most of the patients showed excellent results (12patients, $60 \%), 5$ patients $(25 \%)$ falls under good category, 3 patients $(15 \%)$ showed fair results and none of patient showed poor results. The observations and results of present study were compared to other studies. Conclusion: Meticulous intramedullary nailing of fractures of the proximal third of the tibial shaft, using all current surgical principles and techniques, has excellent clinico-radiological outcome and is relatively safe. We recommend a nail similar to a Sirus nail, but with a more proximal bend of the nail and no dynamic interlocking screw hole.

Keywords: intramedullary nailing, proximal third, shaft tibia fractures

\section{Introduction}

Tibia is the most commonly fractured long bone in the body. Among the total tibial fractures, about $5-11 \%$ of fractures occur in the proximal one third of the tibia ${ }^{[1,2]}$

Proximal tibial fractures are caused most commonly due to high energy trauma like road traffic accidents, Fall from Height, Assault and also due to pathological causes like tuberculosis of bone, staphylococcal infections etc. Treatment is more challenging than for more distal fractures, and the rates of compartment syndrome and arterial injury are higher, especially for displaced fractures. May be managed Conservatively by Functional Bracing ${ }^{[3]}$

Number of surgical management options are available for treatment of the proximal one third tibial fractures which vary according to the type of fractures, age group, bone density, soft tissue status and associated complications. These include open reduction and plate osteosynthesis, minimally invasive plate osteosynthesis, external fixators, ring fixators and interlocking nails ${ }^{[4-7]}$.

Fractures of the proximal third of the tibial shaft, by virtue of being high-energy injuries, are less amenable to plating primarily because of soft-tissue problems, and plates delay weight bearing. External fixators can lead to pin-track infections and there are technical difficulties in preserving knee motion in these juxta-articular fractures. Hence, Interlocking nail remains as 
an option with benefits of load sharing, sparing the extraosseous blood supply, lesser chances of infections and avoidance of additional soft-tissue dissection, thereby minimizing the risk of postoperative complications. Also allows early joint mobilization and weight bearing with short hospital stay $[1,6,8,9]$

Unlike intramedullary fixation of diaphyseal fractures of the tibia significant rate of malalignment has been reported with intramedullary nailing of proximal tibia fractures. Interlocking nail in these fractures has the problems of valgus angulation, apex anterior angulation, posterior translation, varus angulation and mal-rotation ${ }^{[10]}$.

Several nailing methods and reduction techniques have been developed to minimize this complication, including the use of an appropriate nail, a proper starting point and insertion angle, blocking screws, unicortical plates, a universal distractor, and alternative positioning and approaches ${ }^{[1,5]}$.

The optimal method of surgical treatment of fractures of the proximal third tibial shaft remains debatable. The goals of treatment are the same as that of all tibial shaft fractures, i.e. anatomical alignment and stable fixation, minimal tissue trauma, early joint motion, early weight bearing and rapid healing. The intramedullary interlocking nail under image intensifier fulfils these objectives.

In the present study we are evaluating the efficacy and results of closed intramedullary interlocking nail in management of Proximal third tibial fractures.

\section{Aim}

To study the clinico-radiological and functional outcome of the patients with proximal one third tibial shaft fractures managed with interlocking nail.

\section{Materials and Method}

The Present study was conducted in the Department Of Orthopaedics, Govt. Mutispeciality Hospital, Sector 16, Chandigarh during the year 2014-2015. In this study 20 patients of either sex with proximal one third tibial shaft fracture were considered. The proximal tibia is defined as the region extending from the articular surface up to 1.5 times the medial to lateral width of the articular surface. This correlated roughly to the proximal $30 \%$ of the entire tibia. All such fractures at or below the tibial tuberosity, with or without intra-articular extension, and also 1 segmental fractures in which the major fragment was in the proximal third of the shaft, were included in the study; 1 pathological fracture was excluded. There were 10 open fractures, of which 4 were Grade 1 and 6 were Grade 2, according to the Gustilo and Andersen classification. All subjects with Grade 1or 2 open fractures underwent initial debridement and primary wound closure over a drain, with delayed nailing after 48-72 h of debridement. All the closed fractures underwent nailing at the earliest opportunity.Each patient subjected to detailed history, clinical examination and necessary investigations including $\mathrm{X}$-rays of the part. The fractures were classified as per AO classification. The affected limb was immobilized by Above Knee POP slab, skin or skeletal traction till the time of surgery.

\section{Study Design}

The study was prospective, observational, time bound, hospital based, randomized study in which cases satisfying the inclusion criteria, admitted in GMSH, Sec.16, Chandigarh during the study period of October 2014 to September 2015 were included. Patients were followed up for a period of 6 months and Johner and Wruh's evaluation Criteria was used to evaluate the outcome of study at the end of 6 Months.

Data collection: After obtaining the Institutional Ethics Committee permission for the study, patients satisfying the inclusion criteria were enrolled in the study. Detailed history of the patient was noted from the patient or the relatives or those accompanying the patient at the time of admission. The patients were subjected to clinical examination and laboratory investigations as mentioned in the visiting schedule format designed for the study.

Visiting schedule: The patients had to undergo followup visits scheduled at 1 month, 3 months and 6 months following the procedure. The patient had to undergo a clinical evaluation at every visit. Radiologic evaluation was compulsory at the first and last visit.

Inclusion and Exlcusion Criteria: Patients fulfilling the following inclusion criteria were included in the study: Skeletally Mature and age group - above 18 years, patients of either sex - male/ female, patients diagnosed clinically and radiologically with unilateral proximal one third tibia fracture for first time in their life., tibial fractures (Closed, Open Gustillo-Anderson Grade 1 \& 2), patients with normal (unfractured, no history of previous involvement of fracture) contralateral lower limb for comparison, patients willing to give informed consent.

Patients falling into the below mentioned criteria were excluded from the study: Skeletally Immature Patients, patients with previous history of tibial fracture will be excluded, patients diagnosed with bilateral tibial bone fracture, causes of tibia fracture other than trauma, like pathological fractures and open fractures (Gustillo-Anderson Grade 3).

\section{Statistical Analysis}

Proportions were compared using Chi square or Fisher's exact test, depending on their applicability. For Normally distributed data; One-way ANOVA followed by Post Hoc multiple comparisons test was used to compare the groups of outcome. Kruskall Wallis test followed by Mann-Whitney $U$ test was used for statistical analysis of skewed continuous variables. All the statistical tests were two-sided and were performed at a significance level of $\alpha=0.05$. Analysis was conducted using IBM SPSS STATISTICS (version 22.0).

\section{Management of Injury and Method of Collection of Data}

Initial management: when the patient attended in emergency or orthopaedics OPD his vital parameters were recorded. An intravenous line was established, tetanus prophylaxis and intravenous antibiotics were given (if needed). Fluid replacement was started and haemorrhage from wound was controlled by pressure bandage. Associated limb, chest, abdomen and head injury was ruled out or taken care as required. The wound over the fracture site was cleaned and dressed. Other wounds if any were taken care.

The affected limb was immobilized by Above Knee POP slab, skin or skeletal traction till the time of surgery. Once the patient settled from acute injury, he/she was shifted to orthopaedic ward.

\section{Pre-operative assessment and planning}

In the ward, detailed history, mode and severity of injury, event and type of trauma to the tissues and detailed examination of affected extremity were recorded. All the 
required routine investigations and radiological examination (standard plain antero-posterior and lateral radiograph) were done. Fracture was classified on the basis of pattern, AO classification and Gustilo-Anderson classification. After pre anaesthetic check up fitness, the patient was planned for surgery at the earliest. Patient information was collected and compiled in detail.

Pre-operative preparation: Patient was kept fasting 6 hours prior to surgery as per anaesthetist advice. Xylocaine sensitivity testing was done and Pre-operative informed consent taken for operative procedure, anaesthesia and its complications. Prophylactic broad spectrum intravenous antibiotic given to the patients an hour before the surgery.

Nail Length estimated preoperatively by Comparison of the opposite un-fractured tibia using anthropometric measurements: length of nail is $20 \mathrm{~mm}$ less than the distance from knee joint line to ankle joint line in normal tibia.

Anaesthesia: Spinal anaesthesia

Operative procedure: Closed Reduction Internal Fixation by Intramedullary Interlocking nail with or without reaming.

\section{Postoperative management}

Patient was kept nil by mouth for 4-6 hours. Intravenous fluids were given as needed. Intravenous antibiotics were continued for 3 days and then oral antibiotics were given for next 5 days. Analgesics were given according to the need of the patient. Head low position was given for first 24 hours. Post-operative radiograph were taken.

The limb was kept elevated and active toe movements were encouraged. The limb was watched for excessive swelling, pain and neurovascular status. First change of dressing was done after 48 to 72 hours of operation. If the suture line was clean, suture removal was done after 10 to 12 days of operation under strict asepsis.

Joint mobile sation was started on the 2 nd postoperative day. Partial Weight bearing was allowed as early as $2^{\text {nd }}$ postoperative day. Increase in load is determined according to fracture pattern and localisation, conditions of soft tissues and quality of bone as well as absence or presence of load induced pain. The time to full weight-bearing was significantly delayed in high-energy and open fractures. Early postoperative mobilization was instituted. Initially isometric exercises, active assisted range of motion exercises were initiated on first post-operative day. Active knee and ankle mobilization was started as soon as patient became pain free. Non weight bearing crutch walking was begun within one week. Partial weight bearing with toe touching (with walker) started as soon as patient tolerated (after 2 weeks postoperatively). Full weight bearing (with both limbs and standing on one limb) was allowed after osseous union seen radiologically (approx 12 weeks postoperatively) or earlier if condition of patient permitted.

\section{Follow up and evaluation}

Patients were reviewed regularly at 1 month, 3 months and 6 months. They were assessed clinically at each follow up. Check $x$ ray was taken at every visit and patient was clinically and radiologically assessed for fracture union, functional outcome and complications. Complications emerged (if any) in preoperative, intraoperative, postoperative, or during follow up period was treated appropriately.

Functional outcome was measured by the Johner and Wruh's Criteria. ${ }^{11}$
The rotational alignment was assessed clinically by checking the relationship of the intercondylar axis with the inter malleolar axis and comparing with that of the normal side. Anteroposterior and lateral radiographs of both Legs were taken in a similar manner, the patella facing upwards, using the standard radiation exposure and tube distance (in the normal subject, the right and left tibia form a mirror image of each other). The contralateral radiograph was used as a template ${ }^{14}$ to show the proximal and distal segments of the original mechanical axis, which was marked on the radiograph of the normal side as a straight line between the centre of knee and centre of the ankle joint (defined as the midpoint of the distal tibial articular surface). This radiograph was turned over and the radiograph of the fracture was laid over it. By superimposing successively the proximal and distal parts of the tibia, the corresponding proximal and distal segments of the original mechanical axis of the tibia were accurately traced onto the radiograph of the fracture. The intersection of the two lines was at the centre of rotation of angulation (CORA), and the angle between them was the true degree of malunion in that plane. If the CORA did not coincide with the centre of the fracture, or if minimal angulation with gross translation caused the CORA to lie outside the field of the radiograph, the mechanical axis after the fracture was marked on the radiograph. The angle between this line and the two related segments of the normal mechanical axis was measured. The malunion was then the difference between these two angles.

The radiographs were analysed by an independent observer uninvolved in the surgery or follow up of the patient, and were re-analysed by the same observer after 4 weeks, blinded to the first result.

The angles were measured to the nearest 0.58 , using a protractor. In this way, inter- and intra-observer errors were avoided. More than 58 of angulation, 108 of rotation and 10 $\mathrm{mm}$ of displacement were considered as mal-alignment. The fracture was considered united if three of four cortices on two radiographic views were continuous.

\section{Following postoperative complications were assessed: Early}

1. Infection (a) superficial (b) deep, Compartment syndrome, Neurovascular injury/ neuropraxia, Thromboembolism/ fat embolism

\section{Delayed}

Delayed union, Mal union, Non union, Shortening of limb more than $1 \mathrm{~cm}$, Stiff knee joint, Instability, Poor function, Hardware failure : (a) bent nail/ nail breakage (b) locking bolt breakage, Deformities (a) angular (b) rotational and pain.

\section{Observations and Results}

The present study consisted of 20 patients with Proximal Third Tibial Shaft Fractures which were managed by Expert Tibial Nail in Department of Orthopaedics, Govt. MultiSpecialty Hospital, Sector 16, Chandigarh between September 2014 to October 2015.

\section{The following observations were made 1. Age distribution}

All the patients of 18 years or above age were included in this study. The mean age of the patients was 33.60 years (standard deviation 11.798) with a range of 19-60 years. Most of the patients were young adults. 


\begin{tabular}{|c|c|c|}
\hline Age (in years) & Frequency & Percentage \\
\hline $18-30$ & 10 & 50 \\
\hline $31-40$ & 6 & 30 \\
\hline $41-50$ & 2 & 10 \\
\hline $51-60$ & 2 & 10 \\
\hline
\end{tabular}

\section{Gender distribution}

Males were found to be more affected in present series $(80 \%)$.

\begin{tabular}{|c|c|c|}
\hline Sex & Frequency & Percent \\
\hline Female & 4 & 20 \\
\hline Male & 16 & 80 \\
\hline Total & 20 & 100 \\
\hline
\end{tabular}

\section{Laterality of fracture}

In present study in $70 \%$ cases (14 cases) right limb was affected.

\begin{tabular}{|c|c|c|}
\hline Side & Frequency & Percent \\
\hline Left & 6 & 30 \\
\hline Right & 14 & 70 \\
\hline Total & 20 & 100 \\
\hline
\end{tabular}

\section{Mode of injury}

In majority of cases $(65 \%)$ mode of injury was RTA. This was followed by fall from height $(20 \%)$.

\begin{tabular}{|c|c|c|}
\hline Mode of Injury & Frequency & Percent \\
\hline Assault & 3 & 15 \\
\hline FFH & 4 & 20 \\
\hline RTA & 13 & 65 \\
\hline Total & 20 & 100 \\
\hline
\end{tabular}

\section{Associated injuries}

Following associated injury were managed accordingly.

\begin{tabular}{|c|c|c|}
\hline Asso. Inj. & Frequency & Percent \\
\hline \#BBFA & 1 & 5 \\
\hline \#Ulna & 1 & 5 \\
\hline Chest & 3 & 15 \\
\hline HI & 3 & 15 \\
\hline NIL & 12 & 60 \\
\hline Total & 20 & 100 \\
\hline
\end{tabular}

\section{Fracture Pattern}

The fracture pattern was classified based on AO/OTA classification.

\begin{tabular}{|c|c|c|}
\hline AO & Frequency & Percent \\
\hline $41 \mathrm{~A} 1$ & 2 & 10 \\
\hline $41 \mathrm{~A} 2$ & 4 & 20 \\
\hline $41 \mathrm{~A} 3$ & 1 & 5 \\
\hline $42 \mathrm{~A} 1$ & 2 & 10 \\
\hline $42 \mathrm{~A} 2$ & 2 & 10 \\
\hline $42 \mathrm{~A} 3$ & 2 & 10 \\
\hline $42 \mathrm{~B} 1$ & 3 & 15 \\
\hline $42 \mathrm{~B} 2$ & 2 & 10 \\
\hline $42 \mathrm{~B} 3$ & 1 & 5 \\
\hline $42 \mathrm{C} 3$ & 1 & 5 \\
\hline Total & 20 & 100 \\
\hline
\end{tabular}

\section{Grade of fracture}

Open Fractures were Graded by Gustilo-Anderson Classification. In the present series $50 \%$ patients (10) had closed fracture, $20 \%$ Grade I \& 30\% Grade II patients were there.

\begin{tabular}{|c|c|c|}
\hline $\mathbf{1}$ & Frequency & Percent \\
\hline C & 10 & 50 \\
\hline I & 4 & 20 \\
\hline II & 6 & 30 \\
\hline Total & 20 & 100 \\
\hline
\end{tabular}

\section{Injury surgery interval}

In the present series duration between injury and surgery varied from being operated after 2 day to 8 days. The mean injury surgery interval was 3.50 days with standard deviation of 1.606 days. This period of delay was utilized towards making the patient fit for surgery besides management of wounds in open fractures.

\begin{tabular}{|c|c|c|}
\hline injury-surgery interval (in days) & Frequency & Percentage \\
\hline 1) 0-2 Days & 6 & 30 \\
\hline 2) 3-5 days & 11 & 55 \\
\hline 3) 6-8 days & 3 & 15 \\
\hline Total & 20 & 100 \\
\hline
\end{tabular}

\section{Duration of surgery}

In the present series duration of surgery ranged from $60-80$ minutes. Mean duration was 67.75 minutes with standard deviation of 7.159 minutes.

\begin{tabular}{|c|c|c|}
\hline duration of surgery (in minutes) & Frequency & Percentage \\
\hline 1) $60-70 \mathrm{~min}$ & 16 & 80 \\
\hline 2) $71-80 \mathrm{~min}$ & 4 & 20 \\
\hline Total & 0 & 100 \\
\hline
\end{tabular}

\section{Total hospital stay}

In present series total hospital stay ranged from 5-12 days. Mean duration of hospital stay was 7.90 days with standard deviation of 2.404 days. The preoperative stay was mainly used for management of associated injuries and making the patient fit for surgery while the post-operative stay of the patient was utilized for physiotherapy and muscle strengthening exercises.

\begin{tabular}{|c|c|c|}
\hline Total hospital stay (in days) & Frequency & Percentage \\
\hline 1) 5-8 & 13 & 65 \\
\hline 2) 9-12 & 7 & 35 \\
\hline Total & 20 & 100 \\
\hline
\end{tabular}

\section{Knee Mobilisation}

Knee Mobilisation was started as early as Next Post-op Day, Ranging from 2-4 days.

\begin{tabular}{|c|c|c|}
\hline Knee Mobolisation(Days) & Frequency & Percent \\
\hline 2 & 9 & 45 \\
\hline 3 & 9 & 45 \\
\hline 4 & 2 & 10 \\
\hline Total & 20 & 100 \\
\hline
\end{tabular}

\section{Full weight bearing}

In the present series full weight bearing time was 4-12 weeks, with $65 \%$ patients within 6 weeks of Surgery.

\begin{tabular}{|c|c|c|}
\hline full weight bearing (in weeks) & Frequency & Percentage \\
\hline 1) 4-6 weeks & 13 & 65 \\
\hline 2) 7-9 weeks & 6 & 30 \\
\hline 3) $>9$ weeks & 1 & 5 \\
\hline Total & 20 & 100 \\
\hline
\end{tabular}

\section{Time of fracture union}

The union of fracture was assessed by standard radiological 
and clinical criteria (Edwards 1965; Court Brown et al 1990). Due to presence of nail we couldn't stress the fracture site; hence loss of pain on walking was deemed a better clinical indicator of union (Bradford Henley 1989). In the present series union time was $12-18$ weeks.

\begin{tabular}{|c|c|c|}
\hline time of fracture union (in weeks) & Frequency & Percentage \\
\hline 1) 12-14 weeks & 13 & 65 \\
\hline 2) 15-17 weeks & 5 & 25 \\
\hline 3) $>17$ weeks & 2 & 10 \\
\hline Total & 20 & 100 \\
\hline
\end{tabular}

\section{Time of fracture union (in wks)}

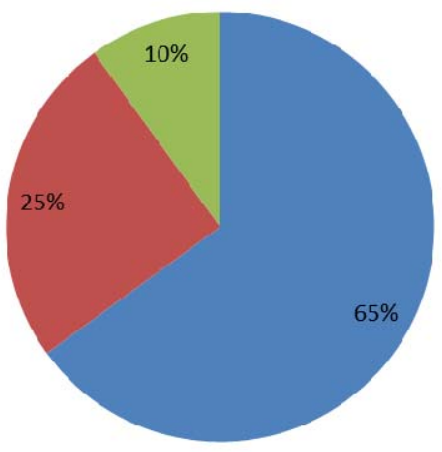

12-11 wks

15-17 wks

$>17$ wks

\section{Pain}

In the present series 7 cases complained of Moderate knee pain, managed by oral Analgesics.

\begin{tabular}{|c|c|c|}
\hline Pain & Frequency & Percent \\
\hline Moderate & 7 & 35 \\
\hline None & 11 & 55 \\
\hline Occasional & 2 & 10 \\
\hline Total & 20 & 100 \\
\hline
\end{tabular}

\section{Infection}

In the present series in three cases we found deep infection for which the patient was admitted and intravenous antibiotics were given and eventually the infection was controlled. In 3 cases infection was superficial and was controlled by oral antibiotics.

\begin{tabular}{|c|c|c|}
\hline Infection & Frequency & Percent \\
\hline None & 14 & 70 \\
\hline Sup. Skin & 3 & 15 \\
\hline Yes & 3 & 15 \\
\hline Total & 20 & 100 \\
\hline
\end{tabular}

\section{Varus/valgus deformity}

In the present series we found angulation deformity (varus/valgus) $>5^{0}$ in 5 cases, of which in 3 cases it was $>10^{\circ}$.

\begin{tabular}{|c|c|c|}
\hline Deformity & Frequency & Percent \\
\hline$>10$ & 3 & 15 \\
\hline $6-10$ & 2 & 10 \\
\hline $2-5$ & 11 & 55 \\
\hline None & 4 & 20 \\
\hline Total & 20 & 100 \\
\hline
\end{tabular}

\section{Antero-Poterior deformity}

In the present series we found Antero-Posterior deformity $>10^{\circ}$ in 5 cases, of which in 1 case it was $>20^{\circ}$.

\begin{tabular}{|c|c|c|}
\hline Ant.-Post. & Frequency & Percent \\
\hline$>20$ & 1 & 5 \\
\hline $11-20$ & 4 & 20 \\
\hline $6-10$ & 4 & 20 \\
\hline $0-5$ & 11 & 55 \\
\hline Total & 20 & 100 \\
\hline
\end{tabular}

\section{Rotation}

In the present series we found Internal Rotation deformity $>10^{\circ}$ in 3 cases, of which in 1 case it was $>20^{\circ}$.

\begin{tabular}{|c|c|c|}
\hline Rotation & Frequency & Percent \\
\hline$>20$ & 1 & 5 \\
\hline $11-20$ & 3 & 15 \\
\hline $6-10$ & 4 & 20 \\
\hline $0-5$ & 12 & 60 \\
\hline Total & 20 & 100 \\
\hline
\end{tabular}

\section{Shortening}

In the present series we found Shortening of $>20 \mathrm{~mm}$ in one case.

\begin{tabular}{|c|c|c|}
\hline Shortening & Frequency & Percent \\
\hline$>20$ & 1 & 5 \\
\hline $11-20$ & 4 & 20 \\
\hline $0-10$ & 15 & 75 \\
\hline Total & 20 & 100 \\
\hline
\end{tabular}

\section{Range of knee motion}

In the present series in most of our cases flexion at knee was not affected $\left(>120^{\circ}\right)$. In 4 cases it was $<90^{\circ}$.

\begin{tabular}{|c|c|c|}
\hline Knee ROM & Frequency & Percent \\
\hline$<75$ & 1 & 5 \\
\hline $90-75$ & 4 & 20 \\
\hline$>90$ & 3 & 15 \\
\hline Full & 12 & 60 \\
\hline Total & 20 & 100 \\
\hline
\end{tabular}

\section{Range of ankle motion}

In the present series ankle motion restricted in 6 cases with one case restricted to $<50^{\circ}$.

\begin{tabular}{|c|c|c|}
\hline Knee ROM & Frequency & Percent \\
\hline$<50$ & 1 & 5 \\
\hline $75-50$ & 5 & 25 \\
\hline$>75$ & 2 & 10 \\
\hline Full & 12 & 60 \\
\hline Total & 20 & 100 \\
\hline
\end{tabular}

\section{Range of Subtalar motion}

\begin{tabular}{|c|c|c|}
\hline Knee ROM & Frequency & Percent \\
\hline$<50$ & 4 & 20 \\
\hline $75-50$ & 4 & 20 \\
\hline$>75$ & 12 & 60 \\
\hline Total & 20 & 100 \\
\hline
\end{tabular}

\section{Gait}

Significant Limp was noticed on walking without aids in 1 case, mild limp seen in 7 cases.

\begin{tabular}{|c|c|c|}
\hline Gait & Frequency & Percent \\
\hline Mild Limp & 7 & 35.0 \\
\hline Normal & 11 & 55.0 \\
\hline Sign. Limp & 2 & 10.0 \\
\hline Total & 20 & 100.0 \\
\hline
\end{tabular}




\section{Complications}

Following post-operative complications were assessed.

\begin{tabular}{|c|c|c|}
\hline Complicaion & Frequency & Percent \\
\hline None & 16 & 80 \\
\hline Infection & 4 & 20 \\
\hline Malalignment & 3 & 15 \\
\hline ROM & 3 & 15 \\
\hline Total & 20 & 100.0 \\
\hline
\end{tabular}

\section{Results}

In the present series all the patients were followed up for 6 month period and periodically assessed clinically and radiologically. After the end of 6 months follow up most of the patients showed excellent results (12patients, 60\%), 5 patients $(25 \%)$ falls under good category, 3 patients $(15 \%)$ showed fair results and none of patient showed poor results.

\begin{tabular}{|c|c|c|}
\hline Results & Frequency & Percent \\
\hline Excellent & 12 & 60 \\
\hline Good & 5 & 25 \\
\hline Fair & 3 & 15 \\
\hline Total & 20 & 100 \\
\hline
\end{tabular}

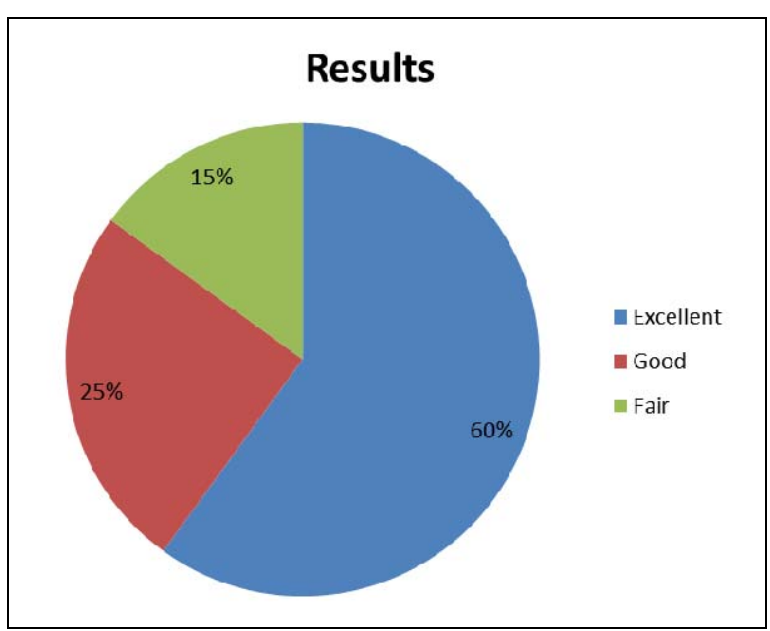

Discussion

The present study was undertaken to determine efficacy of Interlocking Nail in management of Proximal Third Tibial Shaft Fractures. We evaluated our results and compared them with those obtained by various other similar studies. Our analysis is as follows:

Age distribution: Present study revealed the mean age of patients with such injuries to be $\mathbf{3 3 . 6 0}$ years (range 19-60 years). It is comparable with a study on similar fractures conducted by below authors.

\begin{tabular}{|c|c|c|c|}
\hline STUDY & MIN & MAX & Mean \\
\hline${\text { Vidyadhara S } \text { et al. }{ }^{[1]}}^{1]}$ & 18 & 67 & 43 \\
\hline Nork Se et al. ${ }^{15]}$ & 19 & 73 & 42 \\
\hline Lindvall E et al. ${ }^{[16]}$ & 18 & 60 & 36.41 \\
\hline Meena Rc et al. ${ }^{[2]}$ & 18 & 65 & 39 \\
\hline Present & 19 & 60 & 33.6 \\
\hline
\end{tabular}

Sex Distribution: Present study shows male preponderance $(80 \%)$ for such kind of injuries were possibly to the fact of male dominance over the female in traveling, occupational injures etc.

\begin{tabular}{|c|c|c|c|c|c|}
\hline Study & Male & Female & Total & P-Value & (comparison with present study) \\
\hline VIDYADHARA S et al. ${ }^{[1]}$ & 39 & 6 & 45 & 0.711 & \\
\hline NORK SE et al. ${ }^{[15]}$ & 28 & 7 & 35 & 1 & \\
\hline LINDVALL E et al. ${ }^{[16]}$ & 17 & 5 & 22 & 1 & \\
\hline MEENA RC et al. ${ }^{[2]}$ & 14 & 5 & 19 & 0.716 & \\
\hline PRESENT & 16 & 4 & 20 & & \\
\hline
\end{tabular}

\section{Mechanism of Injury}

In our study $65 \%$ of cases attributed to RTA, $20 \%$ to fall from

height and $15 \%$ to assault.

\begin{tabular}{|c|c|c|c|c|c|c|c|}
\hline MOI & RTA & FFH & Assault & Crush & Sport & Total & p-value \\
\hline NORK SE et al. ${ }^{[15]}$ & 33 & 2 & 0 & 0 & 0 & 35 & 0.0626 \\
\hline LINDVALL E et al. ${ }^{[16]}$ & 16 & 2 & 1 & 2 & 1 & 22 & 0.2988 \\
\hline PRESENT & 13 & 4 & 3 & 0 & 0 & 20 & \\
\hline
\end{tabular}

Grade of Fracture

Grade I \& 30\% Grade II patients.

Present study shows 50\% patients with closed fracture, $20 \%$

\begin{tabular}{|c|c|c|c|c|c|c|c|c|c|}
\hline Closed/Open & Closed & I & II & IIIA & IIIB & IIIC & Total & Chi Sq wrt present & p- value wrt present \\
\hline VIDYADHARA S et al. ${ }^{[1]}$ & 18 & 7 & 8 & 12 & 0 & 0 & 45 & 6.78 & 0.079 \\
\hline NORK SE et al. ${ }^{[15]}$ & 22 & 1 & 1 & 7 & 3 & 1 & 35 & 18.1 & 0.003 \\
\hline LINDVALL E et al. ${ }^{[16]}$ & 10 & 3 & 3 & 4 & 2 & 0 & 22 & 7.06 & 0.133 \\
\hline PRESENT & 10 & 4 & 6 & 0 & 0 & 0 & 20 & & \\
\hline
\end{tabular}

Fracture Patterns: In Present study AO/OTA 41 and 42 fractures were included.

\begin{tabular}{|c|c|c|c|c|c|c|c|}
\hline AO/OTA & 41A1 & 41A2 & 41A3 & 41C2 & 42 & Total & \\
\hline NORK SE et al. ${ }^{[15]}$ & 0 & 5 & 7 & 3 & 22 & 37 & 0.1108 \\
\hline PRESENT & 2 & 4 & 1 & 0 & 13 & 20 & \\
\hline
\end{tabular}


Duration of surgery: The average surgical time was 67.75 minutes. It is comparable with the average of 81.57 minutes taken by Meena et al in their study.

\begin{tabular}{|c|c|c|c|}
\hline Duration Of Sx(min) & Minimum & Maximum & Mean \\
\hline MEENA RC et al. ${ }^{[2]}$ & 60 & 110 & 81.57 \\
\hline PRESENT & 60 & 80 & 67.75 \\
\hline
\end{tabular}

Duration of Hopital stay: In present study total hospital stay ranged from 5-12 days. Comparable to that in study by Meena $\mathrm{RC}$ et al. ${ }^{[2]}$

\begin{tabular}{|c|c|c|c|}
\hline Hospital Stay(Days) & Minimum & Maximum & Mean \\
\hline MEENA RC et al. ${ }^{\left[{ }^{2}\right]}$ & 2 & 8 & 4.1 \\
\hline PRESENT & 5 & 12 & 7.9 \\
\hline
\end{tabular}

\section{Fracture union}

The average time for fracture union in various studies conducted using various methods was 10-36 weeks. Our study had fracture union at 12-18 weeks which were comparable with studies.

\begin{tabular}{|c|c|c|c|c|c|}
\hline \#Union & Min & Max & Mean & Rate $\%$ & p- value wrt present \\
\hline VIDYADHARA S et al. ${ }^{[1]}$ & 12 & 36 & 17.2 & & 0.1626 \\
\hline LINDVALL E et al. ${ }^{[16]}$ & & & & 96 & \\
\hline MEENA RC et al. ${ }^{[2]}$ & 10 & 30 & 18.26 & 94.7 & 0.1809 \\
\hline PRESENT & 12 & 18 & & & \\
\hline
\end{tabular}

Pain: Present study reported moderate Knee Pain in 7 cases.

\begin{tabular}{|c|c|c|c|c|c|}
\hline & & & \multicolumn{1}{|c|}{ Chi Sq wrt present } & p- value wrt present \\
\hline Pain & None & Occasional & \multicolumn{2}{|c|}{ Moderate } & \\
\hline VIDYADHARA S et al. ${ }^{[1]}$ & 42 & 1 & 2 & 13.6 & $0.001^{* *}$ \\
\hline Present & 11 & 2 & 7 & & \\
\hline
\end{tabular}

Infection: Infection rate is comparable to similar studies.

\begin{tabular}{|c|c|c|c|}
\hline Infection & None & SSI & Deep \\
\hline NORK SE et al. ${ }^{[15]}$ & 35 & 0 & 2 \\
\hline LINDVALL E et al. ${ }^{[16]}$ & 17 & 5 & 0 \\
\hline MEENA RC et al. ${ }^{[2]}$ & 19 & 0 & 0 \\
\hline PRESENT & 14 & 3 & 3 \\
\hline
\end{tabular}

Malalignment: Malalignmen with Valgus and Apex Anterior were Seen Commonly and is comparable.

\begin{tabular}{|c|c|c|c|c|c|c|}
\hline Malalignment & Valgus & Varus & Anterior & Posterior & Rotation & Shortening \\
\hline VIDYADHARA S et al. $^{[1]}$ & 4 & 1 & 7 & 5 & 1 & 0 \\
\hline NORK SE et al. ${ }^{[15]}$ & 1 & 2 & 0 & 0 & 0 & 0 \\
\hline${\text { LINDVALL E } \text { et al. }{ }^{[16]}}^{16}$ & 2 & 0 & 8 & 0 & 0 & 0 \\
\hline PRESENT & 5 & 0 & 7 & 2 & 4 & 5 \\
\hline
\end{tabular}

\section{Results}

The results in terms of $\%$ of acceptable and non-acceptable are comparable to standard studies with more Acceptable Results.

\begin{tabular}{|c|c|c|}
\hline Result & Acceptable & Not Acceptable \\
\hline Vidyadhara S et al. $^{[1]}$ & 96 & 4 \\
\hline Nork Se et al. ${ }^{[16]}$ & 91.9 & 8.1 \\
\hline PRESENT & 85 & 15 \\
\hline
\end{tabular}

NB: The excellent and good results have been tabulated as acceptable and the fair and poor results as not acceptable for easier comprehension.

\section{Conclusion}

In view of the results obtained and complications encountered, we conclude that intramedullary nailing of proximal third tibial fractures, meticulously performed while using current surgical principles and techniques, yields excellent clinico-radiological outcomes with minimal complications, when compared with the results of older series on nailing. Although intramedullary nailing cannot be declared ideal for all fractures of the proximal third of the tibial shaft, its inherent advantages should be respected. In the treatment of such fractures, we recommend the use of a nail similar to a Sirus nail but with a more proximal bend (within $6 \mathrm{~cm}$ of the upper end) and no dynamic screw hole. This nail design needs to be further standardised with biomechanical testing before clinical use.

\section{Reference}

1. Vidyadhara S, Rao SK. Prospective study of the clinicoradiological outcome of interlocking nail in proximal third tibial shaft fractures. Injury, Int. J. Care Injured. 2006; 37:536-42

2. Meena RC, Meena UK, Gupta GL, Gahlot N, Gaba S. Intramedullary nailing versus proximal plating in the management of closed extra-articular proximal tibial fracture:a randomized controlled trial. J Orthop Traumatol. 2015; 16(3):203-8.

3. Martinez A, Sarmiento A, Latta LL. Closed Fractures of the Proximal Tibia Treated with a Functional Brace. Clin Orthop Rel Res. 2003; 417:293-302.

4. Tytherleigh-Strong GM, Keating JF, Court-Brown CM. Extraarticular fractures of the proximal tibial diaphysis:their epidemiology, management and outcome. J R Col Surg Edinb. 1997; 42:334-8.

5. Bal GK, Kuo RS, Chapman JR, Henley MB, Benirschke SK, Claudi BF. The anterior T frame external fixator for high energy proximal tibial fractures. Clin Orthop Relat Res. 2000; 380:234-40.

6. Bhandari M, Audige L, Ellis TJ, Hanson B. Operative 
Treatment of Extra-Articular Proximal Tibial Fractures. J Orthop Trauma. 2003; 17(8):591-5.

7. Peindl RD, Zura RD, Vincent A, Coley ER, Bosse MJ, Sims SH. Unstable proximal extraarticular tibia fractures-a biomechanical evaluation of four methods of fixation. J Orthop Trauma. 2004; 18:540-5.

8. Buehler K, Green J, Woll T, Duwelius P. A Technique for Intramedullary Nailing of Proximal Third Tibia Fractures. J Orthop Trauma. 1997; 11(3):218-23.

9. Hiesterman TG, Shafiq BX, Cole PA. Intramedullary Nailing of Extra-articular Proximal Tibia Fractures. J Am Acad Orthop Surg. 2011; 19(11):690-700.

10. Freedman EL, Johnson EE. Radiographic analysis of tibial fracture malalignment following intramedullary nailing. Clin Orthop. 1995; 315:25-33.

11. Johner R, Wruhs O. Classification of Tibial Shaft Fractures and Correlation with Results after Rigid Internal Fixation. Clin Orthop Rel Res. 1983; 178:7-25.

12. Sidharthan S, Sujith A, Rathod A, Pathak R. Management Of High Energy Tibial Fractures Using The Ilizarov Apparatus. The Internet J of Orthop Surg. 2004; 2(2).

13. Batta V, Dwyer AJ, Gulati A, Prakash J, Mam MK, John B. No difference in the long term final functional outcome after nailing or cast bracing of high energy displaced tibial shaft fractures. J Trauma Manag Outcomes. 2012; 6(1):5.

14. Milner SA. A More Accurate Method Of Measurement Of Angulation After Fractures Of The Tibia. J Bone Joint Surg. 1997; 79B(6):972-4.

15. Nork SE, Barei DP, Schildhauer TA, Agel J, Holt SK, Schrick JL et al. Intramedullary nailing of proximal quarter tibial fractures. J Orthop Trauma. 2006; 20:52328.

16. Lindvall E, Sanders R, DiPasquale T, Herscovici D, Haidukewych G, Sagi C. Intramedullary Nailing Versus Percutaneous Locked Plating of Extra-Articular Proximal Tibial Fractures: Comparison of 56 Cases. J Orthop Trauma. 2009; 23:485-92. 